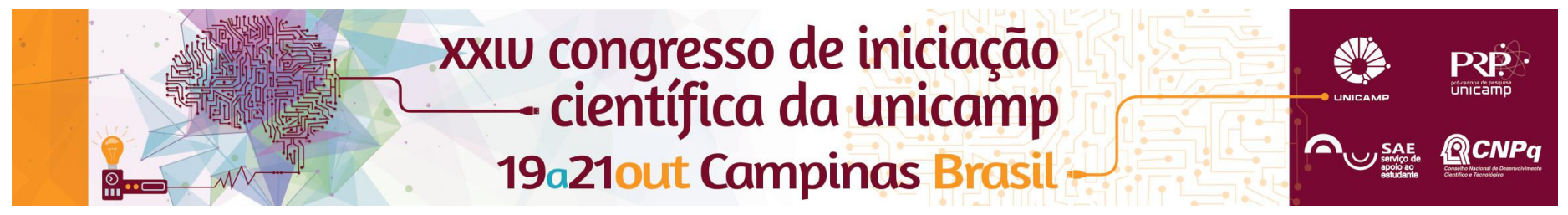

\title{
CORRELAÇÃO ENTRE RESISTÊNCIA A TRAÇÃO E VELOCIDADE DE PROPAGAÇÃO DE ONDAS ULTRASSÔNICAS EM MUDAS DE EUCALIPTO.
}

\author{
Luana Paschoal*, Raquel Gonçalves, Rafael G. M. Lorensani.
}

\begin{abstract}
Resumo
Uma das pesquisas em desenvolvimento no Laboratório de Ensaios não destrutivos da FEAGRI (LabEND), em nível de doutorado, visa verificar a viabilidade de inferir propriedades de árvores adultas à partir de ensaios feitos em mudas. Nas mudas são obtidos parâmetros acústicos e características das plantas, como o diâmetro e a densidade. No caso das árvores adultas as propriedades que se deseja inferir são a densidade, a resistência e a rigidez. Sendo assim, é importante verificar se existe correlação entre os parâmetros obtidos nas mudas e suas as propriedades de resistência e de rigidez, uma vez que a ausência destas correlações indicaria menores chances de se predizer tais propriedades em árvores adultas à partir de ensaios em mudas. Assim, esse projeto de iniciação científica teve como objetivo avaliar a correlação entre a resistência e a rigidez à tração e a velocidade de propagação das ondas ultrassônicas em mudas de eucalipto. Para os ensaios de tração foram utilizadas mudas de eucalipto, com 3 meses de idade. Os resultados mostram que modelos de regressão incorporando apenas a velocidade não explicam adequadamente a variabilidade da resistência e da rigidez das mudas, mas ao incorporar a densidade e o diâmetro os modelos são estatisticamente significativos.
\end{abstract}

\section{Palavras-chave \\ Eucalipto, clones, ultrassom}

\section{Introdução}

Uma das pesquisas em desenvolvimento no Laboratório de Ensaios não destrutivos da FEAGRI (LabEND), em nível de doutorado, visa verificar a viabilidade de inferir propriedades de árvores adultas à partir de ensaios feitos em mudas. Nas mudas são obtidos parâmetros acústicos e características das plantas, como o diâmetro e a densidade. No caso das árvores adultas as propriedades que se deseja inferir são a densidade, a resistência e a rigidez. Sendo assim, é importante verificar se existe correlação entre os parâmetros obtidos nas mudas e suas as propriedades de resistência e de rigidez, uma vez que a ausência destas correlações indicaria menores chances de se predizer tais propriedades em árvores adultas à partir de ensaios em mudas. Assim, esse projeto de iniciação científica teve como objetivo avaliar a correlação entre a resistência e a rigidez à tração e a velocidade de propagação das ondas ultrassônicas em mudas de eucalipto. Para os ensaios de tração foram utilizadas mudas de eucalipto, com 3 meses de idade. Os resultados mostram que modelos de regressão incorporando apenas a velocidade não explicam adequadamente a variabilidade da resistência e da rigidez das mudas, mas ao incorporar a densidade e o diâmetro os modelos são estatisticamente significativos.

\section{Resultados e Discussão}

Os modelos de regressão simples, utilizando como variável independente apenas a velocidade de propagação das ondas de ultrassom obtida nas mudas $\left(V_{m}\right)$, não foram estatisticamente significativos ( $P$-valor > 0,05). No entanto, ao utilizar a regressão múltipla, incorporando, além da velocidade, a densidade básica $(\rho)$ e o diâmetro da muda $(\phi)$, foi possível obter modelos de correlação estatisticamente significativos, e que explicam mais de $80 \%$ da variabilidade do módulo de elasticidade $\left(\mathrm{E}_{\mathrm{T}}\right)$ e da resistência $\left(\mathrm{f}_{\mathrm{T}}\right)$ na tração (Tabela 1).

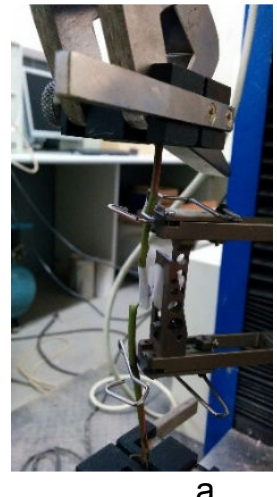

a

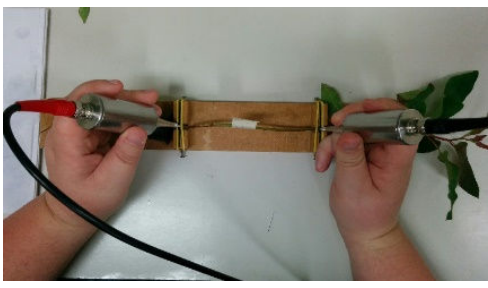

b
Figura 1. Ensaio de tração (a) e de ultrassom (b) em mudas

Tabela 1. Modelos e parâmetros da regressão correlacionando o modulo de Elasticidade ( $\left.\mathrm{E}_{\mathrm{T}}\right)$ e a resistência $\left(\mathrm{f}_{\mathrm{T}}\right)$ à tração utilizando como variáveis independentes a velocidade de propagação das ondas de ultrassom $(\mathrm{Vm})$, a densidade básica $\left(\rho_{\mathrm{B}}\right)$ e o diâmetro $(\phi)$ das mudas

\begin{tabular}{|c|c|c|}
\hline Modelo & P-valor & $\mathbf{R}^{\mathbf{2}}(\%)$ \\
\hline $\mathrm{E}_{\mathrm{T}}=1,26 \mathrm{~V}_{\mathrm{m}}+8402 \rho_{\mathrm{B}}-1426 \phi$ & 0,00 & 82 \\
\hline $\mathrm{f}_{\mathrm{T}}=0,011 \mathrm{~V}_{\mathrm{m}}+31,3 \rho_{\mathrm{B}}-5,28 \phi$ & 0,00 & 89 \\
\hline
\end{tabular}

\section{Conclusões}

Tendo em vista que somente um clone foi analisado, os modelos obtidos ainda são preliminares. No entanto foi possível verificar que modelos de regressão incorporando apenas a velocidade não explicam adequadamente a variabilidade da resistência $e$ da rigidez das mudas, mas ao incorporar a densidade e o diâmetro os modelos são estatisticamente significativos.

\section{Agradecimentos}

Ao CNPq e à FAPESP (2013/03449-9).pelas bolsas de estudo e à International Paper pelo material da pesquisa. XXIV Congresso de Iniciação Científica da UNICAMP 